\title{
Herding in Crisis in the Himalaya
}

\author{
Jiban Mani Poudel
}

\begin{abstract}
This paper focuses on the change and transformation of herding over the last seven decades to the Nhāson Valley of Manang based on an ethnographic study in 2018. The findings reveal that herding as a traditional source of living for the mountain dwellers, has gradually been transformed due to the linkage to wider political and economic processes, namely, the changes in open-border policy between China and Nepal, the intervention of state programs and its policies toward the people, the expansion of trade and business with tourism, commercialization of Himalayan herbs, climate change, and intervention of agroforestry in the community forest and plantation of highvalue cash crops in private lands, youth opportunities to work in aboard. Hence, looking at herding by placing it in a particular place or in isolation by ignoring the wider political and economic processes is misleading, one-sided, and superficial. Moreover, the market economy and the state intervention have brought some new livelihood opportunities to the Himalayan dwellers, although the questions always remain in its sustainability.
\end{abstract}

Keywords: crisis, herding, Himalaya region, political-economic process, sustainability

\section{Background of the Study}

Herding is one of the pillars of living for the people of the Himalayan region of Nepal (Messerschmidt, 1976; von Fürer-Haimendroef, 1978; Levine, 1989; Brower, 1993; Stevens, 1993; Miller, 1995, 1998; Bishop, 1998; Aryal et al., 2013; Chhetri, 2014; Poudel, 2018; Bhusal et al., 2018; Hellman, 2019). The environmental factors such as wider accessibility to meadows ${ }^{1}$ and limited agricultural land and harsh climate have been forced the Himalayan dwellers to adapt to animal husbandry for living. However, it is gradually declining due to loss of human resources, changing pattern of trade, and decreasing forest reserve (Messerschmidt, 1974), the migration of youth and modern education (Bishop, 1998; Dorji et al., 2020), the influence of tourism (Stevens, 1993; Spoon, 2013), overgrazing of meadows (Aryal et al., 2013), and conflict with community forests (Bhusal et al., 2018). Except for a few, these studies cited above have not ventured to talk about the changes in herding in the Himalayan region of Nepal. The decline of herding in the region neither happened at a specific time nor any single factor was responsible for it. The times and other multiple actors, what I mean political, economic, and sociocultural contexts, are responsible for it.

Studies in the Himalayan region have largely examined herding in terms of subsistence strategies that facilitate the exploitation of the Himalayan environmental resources to assure biological survival (Brower, 1993; Stevens, 1993; Miller, 1995, 1998; Basnet and Chaudhary, 2017). These studies are somewhat useful to understand livestock management in the Himalaya, but not sufficient. They have largely overlooked the local-global interface essential to examining the herding and its change. Because herding

1. Pastures in high altitude areas possess about 80 percent of Nepal's rangelands (Banjade and Paudel, 2008) is not purely a local phenomenon; it is the product of a particular political-economic process, and those same processes shape it (Poudel, 2016). Goldman and Turner (2011) argued, "some phenomena seem to be isolated but impacting and impacted by decision-making processes, politics, and technology around the world" (pp.1). Therefore, the influences of the state intervention and economic forces will be helpful to understand the transformation of herding in the Nhāson Valley of Manang district, Nepal.

The combination of agriculture, herding, and trade has been the foundation of the economy in the Himalayan region (Messerschmidt, 1974; Fisher, 1987; Stevens, 1993; Bauer, 2004; Poudel, 2016). However, changes have been undergone in livelihood strategies, including the herding in the Himalayan region, and the Nhāson Valley in particular over the last seven decades due to influences of different phenomena. As a result, the number of herds and their size has been declining (Bauer, 2004; Hellman, 2019; Pandey \& Chetri, 2005). In this context, this paper tries to answer some fundamental questions. How did international political changes (e.g., the takeover of Tibet by China), state intervention (a special privilege for free trade to Ngisyangba, the establishment of schools for modern education, food depot, and road construction) and market economy (flourish of tourism, trade, and business, out-migration of young people, plantation of high-value crops in traditional grazing lands) affect herding in the valley? What did the herders do to cope with the induced challenges? Was/is the new strategy sustainable for the mountain dwellers? These are some simple questions demanding answers. Thus, this paper examines the transformation of herding in the Nhāson Valley through an examination of the nexus of the local-global interface that can provide us a valuable set of insight on underlying factors for herding transformation and change in the Himalaya region of Nepal through time and space. 


\section{The Study Area and Research Methods}

The Nhāson Valley lies in South-East of Manang district $^{2}$. The district covers a wide vertical zone from 1,645 meters to 8,125 meters from the sea level (His Majesty's Government of Nepal (HMG/N), 2000\}. The largest proportion of land is barren (44.18\%), and the secondlargest are mountain and rock land (39.60\%). The lands covered with pastures, forests, bushes, and agriculture are $8.23 \%, 5.42 \%, 2.09 \%$, and $0.46 \%$ respectively $[\mathrm{HMG} / \mathrm{N}$ 2057/58 BE (2000-2002 CE) ]. The land-use patterns have also supported animal husbandry for livelihood in the district, including the Nhāson Valley. Moreover, the wider variations in topography and climatic characters have also been playing a significant role in the herding of different livestock like yak, cho (a hybrid of yak and cow), zebu cattle, sheep, goat, mule, and horse for ages.

In 2018, there were 16 settlements. Out of them, seven settlements (Gherang, Gyalanchok, Nache, Tache, Thanchok, Tilche, and Unash) were largely depended on agro-pastoralism rather than a tourism-based business. The intensive study was done in Nache village. My earlier study on local perceptions, knowledge, and adaptation on climate change in the same valley also helped me to identify highly depended village on animal husbandry for a living. I visited the village in 2018, talked with the herders and villagers, and collected information on the size and types of herds, the number of livestock, grazing lands, and movement of herds according to seasons and transformation of herding overtimes. It helped me to understand the current herding practice among the villagers. During that time, I also observed some meadows where villagers moved their herds for grazing in different seasons.

This study was to explore the transformation of herding in time sequence concerning the state intervention, influence of the market economy, and climate change. Therefore I widened my study area to other villages of the valley. I talked with herders and villagers about the changes and transformation of herding in the valley by relating it with different socio-political and economic contexts including control over Tibet by China, the privilege of international trade to Ngisyangba, the establishment of schools for modern education, tourism, out-migration of youth, political change of Nepal in 1990, Ethnic Movement and Maoist Movement after the 1990s, plantation of high-value cash crops by Community Forest User Groups and private landowners in winter grazing-lands. As recommended by the local villager, I talked with five herders about herding practices of the past and the present in the valley.

I went to the site with a topo-map. In the field, I requested the herders to locate the pastures (see figure $1)$. It helped me find out the major pastures where the Nache herders graze their herds in different seasons and the impacts of climate change on herding and their coping strategies.

\footnotetext{
2. 'Nhāson', the village name, is derived from the Gurung's two words ' $n h \bar{a}$ ' (villages) and 'son' (three), literary meaning 'three villages'. Nhāson, therefore, traditionally denotes the three villages, namely, Tache, Nache, and Tilche.

3. BE refers Before Era and CE to Common Era.
}

\section{Herding at Nache}

Herding was the earliest livelihood adaptive strategy of Gurungs (Messerschmidt, 1974 \& 1976). It is an integral part of the local subsistence agricultural system and trade in the Nhāson Valley including Nache village. Agriculture and trade, therefore, would be impossible without livestock. Like other mountain regions of Nepal, yak, nak (female yak), cho (male cross-breed of yak and zebu cow), cho-aama (female cross-breed of yak and zebu cow), cow, ox, goat, sheep, and horse are commonly raised for different purposes. For example, yak, sheep, and goats are for meat, wool, manure, and $\mathrm{cash}^{4}$; nak for reproduction; cow for ox and hybrid production and manure; ox for draft energy and manure; and cho-aama for dairy products and manure; and cho for making cash by selling them. Horses are for transportation and social prestige. Besides material usages, some livestock, especially sheep, are needed for sacrificial offerings to the local deities in various rituals to maintain harmonious relations between cosmology and the living world.

In the valley, the herding has been shaping and reshaping by a larger political-economic process over the last seven decades and more. For example, yak and cho raising was almost stopped when Tibet became a part of China, cattle and sheep/goat herds were declined when the people of upper Manang got the special privileges for trade by the government, the establishment of schools for modern education, the opening of Manang to tourists, and youth out-migration for works. Yak herds have again flourished from 2003 after the 1990s the political change and sociocultural movements (I will discuss more detail later). This reflects that herding is, therefore, not a local, place-specific, and isolated phenomenon. It is connected with the state and its policies and market economy; what Beirsack (2006) is termed 'local-global interface'.

There were 39 households at Nache village in 2018, of which 20 households were involved in herding. Out of 20 herder households, 13 had yak herds, six had zebu-cow herds and only one household had cho-aama (crossbreed of yak and zebu cow). The total livestock in the village was 398 of which 227 were yak, 156 heads were zebu cow and 15 heads were choaama. The largest yak herder had 38 heads of yak and the small had only four heads. Likewise, the largest zebu cow herds had 59 heads whereas the smallest one had only nine heads. There were around 300 heads of sheep and goats in the village. It was managed by the villagers jointly in a single herd when individual ownership of sheep herds was declined. Moreover, 24 horses were found in five households ranging from 14 to 2 heads per household.

4. In the valley, farmlands are located less than 3,000 meters from the sea level where yak hardly survive due to physiological characters. Like other highland agropastoralists, yak's dung is not used for manure in the valley. In 2018, I did not see using yak's wool for weaving woolen mats. 
Table 1: Distribution of Households with Cattle Herds at Nache Village

\begin{tabular}{|l|l|l|l|l|}
\hline \multirow{2}{*}{ Types of herds } & \multicolumn{2}{|l|}{$\begin{array}{l}\text { Households } \\
\text { with cattle }\end{array}$} & $\begin{array}{l}\text { No of } \\
\text { cattle }\end{array}$ & $\begin{array}{l}\text { Ave r a ge } \\
\text { cattle per } \\
\text { household }\end{array}$ \\
\cline { 2 - 4 } & No & \% & & \\
\hline Yak & 13 & 33.3 & 227 & 17.5 \\
\hline Cho-aama & 1 & 2.6 & 15 & 15.0 \\
\hline Cow & 6 & 15.4 & 156 & 26.0 \\
\hline $\begin{array}{l}\text { Household with } \\
\text { herds }\end{array}$ & 20 & 51.3 & 398 & 19.9 \\
\hline $\begin{array}{l}\text { Total } \\
\text { households }\end{array}$ & 39 & 100.0 & 398 & 10.2 \\
\hline
\end{tabular}

Source: Field survey, 2018

\section{Livestock Management}

In Nache village, the management of livestock has been determined by altitudes, climate, physiological characteristics of animals, human resources at households, customary laws and cultural beliefs, presence of predators, grasses, and water resources at pasturelands, used-value of livestock, and gender. The transhuman practice is itself a product of climate, altitudes, and available resources in different altitudes in different seasons as well as human resources for caring livestock (Poudel 2020c). In the winter, the Nache herder cannot get ground grasses to feed their livestock and the available storage fodder also cannot meet an annual demand for fodder for their livestock. Therefore, the management of livestock varies according to seasons and herd size. In the summer season, they exploit distant environments where plentiful and nutritious grasses are enough and easily available to feed the livestock. At that period, the small herds are managed jointly ${ }^{5}$. Two or more households keep their herds together by hiring a herder. In the winter, it is very hard to manage the herds jointly due to a lack of enough fodder and hay. Therefore, each household separate his or her herd and kept it separate. In the valley, I found a strong thiti system (customary laws) and cultural taboo related to herds movement. They regulate the movement of livestock from one grazing area to another. Similarly, the physiological features of animals were not passive actors in livestock management in the Himalayan region.

There is a division of labor related to livestock management among men and women of the Nhāson Valley, although there was no fixed rule ${ }^{6}$. However, livestock management is generally the men's sphere. Men's works include carrying the bamboo mats and heavy equipment needed for making the goth between pastures, cutting firewood, grazing livestock, supervising livestock breeding, making trips to new pastureland, buying and selling livestock, milking cattle, making butter and cheese (rarely done in Nhāson), and shearing of sheep. Women's duties include caring for livestock (collecting grass, watering, cleaning sheds) and harvesting straw (including maize, naked barley, wheat, buckwheat, and sometimes grasses) to feed the livestock.

\section{Pasturelands at Nache}

There are 20 main pasturelands, namely Kulu-danda, Ngemjo-kharka, Wangreu, Wangreche, Wabu-kharka, Lowa-kharka, Kyu-kharka, Prodha-kyu, Ticheu, Kromche, Kyusi, Nache, Nigalaghari, Tham-kharka, Himru-kharka, Khibru-kharka, Noktu-danda, Kejbari, Komlo-kharka, and Klibu-danda of the Nache herders (see Figure 1). As a transhuman community, the Nache herders move their herds for grazing in different pasturelands on a rotational basis according to seasons and nature of herds. In the summer season, for instance, they graze their livestock in higher meadows approximately located about 3,500 meters and above. They move their livestock at Kyusi (approximately 2,700 meters) and Kromche (approximately 3,100-3,200 meters) in the transitional seasons between the winter season and the summer season and vice verse. In the winter season, zebu cattle, sheep, and goats herds are moved to the low altitude pasturelands like Nache, Nigalagahri, Jagat, Chipla, and other pastures located around 2,000 meters and less altitude.

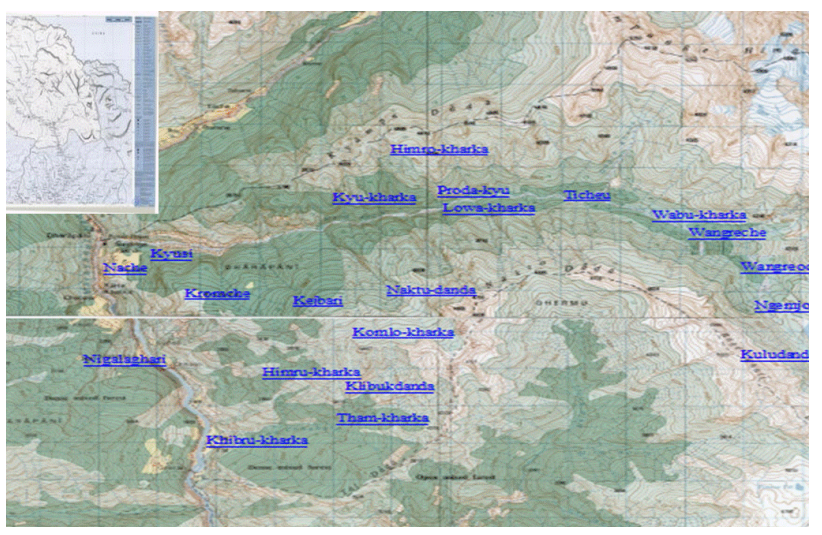

Figure 1: Major Pasturelands of Nache Village

Since, 2016, the movement of the zebu cattle and sheep and goats to Jagat and Chipla ${ }^{7}$ have stopped when the people of the areas planted cardamom ${ }^{8}$, a highly commercial cash crop, inside community forests and private farmlands where the Nhāson herders would use for grazing traditionally. Thereafter, the areas should be restricted to graze that has adversely affected seasonal movement of zebu cattle and sheep/goats herds. However, yak herds are grazed in high pasturelands, i.e., 3,600 meters above throughout a year which has not been affected by restriction on grazing by lowland dwellers.

7. They are located outside the Nhāson Valley, but the herders of the valley had been grazing their herds there for many generations.

8. Nepal Trade Integration Strategy (2016) has recognized large cardamom as the most potential export agro-commodity (Government of Nepal, 2016a). The Agriculture Development Strategy (2015-35) has prioritized it as one of the top three highvalue crops and listed it under the special program (Government of Nepal, 2016b). 


\section{Results and Discussions}

\section{Heyday of Livestock}

Salt-grain trade was common in the Trans-Himalayan region of Nepal until the late 1950s (Gurung, 1976; Fisher, 1987; Schrader, 1987; van Spengen, 1999; Bauer, 2004). However, this was not feasible for all villages located in the trans-Himalayan region. In Manang, there were three valleys - Nar-Phu, Ngisyang, and Nhāson. The first two valleys (Nar-Phu and Ngisyang) did not involve in the salttrade due to harsh passes (van Spengen, 1999). However, the topographical features favored the people of the Nhāson Valley for the trade. Later, it became one of the important centers for salt trade that came across the high pass of Gya La (5,334 m) and Larke La (5,214 m) (Gurung, 1980). There were three salt trade centers in the Nhāson Valley: Bimthang, Thoche, and Timang. Bimthang was the trade center between the Nhāson people and Tibetan salt traders. Tibetan traders would visit Bimthang with wool and salt for exchange with naked barley. Similarly, Timang was center between people of Nhāson and Kaski, southern adjacent district and Thoche, located at the confluence of the Marsyandi River and the Dudhakhola, was another important trade center controlled by a few Lamichane Gurungs of Ghanapokhara, a village of Lamjung District. They were the government's salt trade contractors. Besides Lamichhane families, other villages were also involved in the salt trade in a small amount.

Humans and animals were the main means of transportation. Hilly people from Lamjung and Kaski used to visit the Nhason Valley with grains, especially rice and would exchange it with salt (Gurung, 1980). The exchange rate for salt and grains was in equal amounts in the Nhāson Valley. Sometimes, the Nhāson villagers would themselves travel to Lamjung with salt to exchange with the grain. In Lamjung and Kaski, the exchange rate between salt and grain would be double i.e., one pathi (about $4 \mathrm{~kg}$ ) salt with two pathis $(8 \mathrm{~kg})$ of rice.

Cho and yak were the key means of transportation in Bhimthang and Thoche salt-grain trade route when it was in the climax. Unlike many parts of the trans-Himalayan region, Nhāson people did not use goats and sheep for carrying the loads. They only used cho and yak. They used to carry loads of naked barely from lower parts of Nhāson up to Bimthang and salt from Bimthang to Thoche. This trade was continued until the early 1960s. Thereafter, it began to decline. After the decline of the salt-grain trade in the valley, yak and cho herding were highly suffered and completely vanished in $1981^{9}$ (I will discuss it below).

\section{Herding in Crisis}

The crisis of herding in the Himalayan region started after Tibet became a part of China (von Fürer-Haimendroef, 1978; Fisher, 1987; Miller, 1995, 1998; Bauer, 2004; Poudel, 2016), and the expansion of state intervention and market economy (free trade privilege, opened a school for modern education, opened Manang to foreigners) in Manang (Poudel, 2016). In 1957, the border between China and Nepal was sealed. As a result, salt-grain-salt

9. Khadak Bahadur Gurung was the last cho herder of the valley. He sold his herd in 1981 and invested the money in mules. trade was came to end in the Trans-Himalayan region (von Fürer-Haimendroef, 1978; Fisher, 1987; Bauer, 2004), and Nhāson was not the exception. After the independence of India from the British ruler, the flow of Indian goods including salt was rapidly increased in Nepal. Indian salt was both easily available and economical for hilly people than Tibeat salt (von Fürer-Haimendroef, 1978; Fisher, 1987). The costly Tibetan salt could not compete with cheap Indian salt. The yak and cho, as means of salt-grain transportation in the valley, became useless. The herders began to sell their herds to upland dwellers. By 1964, yak herds completely disappeared from Nhāson, but cho herds remained until 1981.

The political change in Tibet as well as the expansion of Indian market not only suffered from the salt-grain trade in the valley, but also produced a new economic, political, and social crisis. The valley began to lose its regional power moved around the salt-grain trade.

After the decline of the salt-grain trade in 1957, the people of Nhāson were looking for a new option for livelihood. In 1962, the government of Nepal gave the privilege of free trade to the people residing in UpperManang, known as Ngisyangba (Gurung, 1976; van Spengen, 1987 \& 1999). Being the residents of the same district, the people of Nhāson Valley did not have the privilege. However, the people of Nhāson Valley and Ngisyang Valley had the same family names; that is, Gurung and Ghale, even though they were culturally and linguistically distinct groups ${ }^{10}$. The Nhāson people used the common family names tactically to involve in the trade. Almost all males aged 50 to 70 years had a wonderful story about visiting Hong Kong, Singapore, Thailand, and even many parts of Europe. I mean, the people of Nhāson did not intentionally misuse the family's names to get access to the trade privilege, but they had taken it as a mean of coping strategy in the crisis came after border seal by China after the takeover of Tibet and the expansion of Indian salt.

The status of the people of Ngisyang Valley and Nhāson Valley was not the same in the international trade. The first one was traders and the latter one was porters. As porters, they would carry foreign goods to Ngisyangba. On each trip, a person could earn NRs. 5,000-7,000. It was reported that most of the young males were worked as a porter for Ngisyangba during that time. It brought new opportunities to making cash for the people of Nhason but also created a scarcity of potential human resources to care for herds at household. As a result, large herders either sold their herds or reduced their size ${ }^{11}$.

\section{Establishment of School and Decline of Herding}

In the valley, the first school was established in 1962. Notwithstanding, all villagers did not send their

10. Both culturally and linguistically, Ngishyanba were closer to Tibetan people and Nhāson Gurungs to the Gurungs and Ghale of Lamjung, and other hilly regions of Nepal (Gurung 1976; Poudel 2016).

11. In the 1970s, five sheep/goat herds out of seven were disappeared in Tache village due to a shortage of human resources 
children to school until the mid-1970s. They did not see their children's future better secured through education. However, some rich people saw their children's future in modern education. They sent them to schools for modern education. After completed their education, they got jobs at government offices and local schools established in other villages. This was a turning point to push children to modern education. Regarding this, K. Ghale (68), one of my informants shared his experiences like this:

Government opened a school for the people of Nhāson in 1962, even though most of the villagers did not see their children's future better secure by sending them to school as they saw by herding livestock. They considered the modern school as a loss of potential labor-forces for herding and farming. In the mid-1980s, some educated people could grasp new opportunities available in the villages, especially schools and other government offices. That brought changes in attitude toward modern education among the villagers. Thereafter most of the villagers started sending their children to school for modern education.

Modern education not only created a new opportunity for livelihood to the youth, but it appeared as a driver to detach youth from traditional occupation especially herding (Bishop, 1998; Dorji et al., 2020). In the valley, the school used to open from March to November, and herds would be away from the village from April to August. Therefore, children could not attend school by caring for their herds. Thus, they had only one option to choose, i.e., either to go to school for education or to visit the herds for caring livestock. Villagers chose the first option ${ }^{12}$.

Attitude toward pastoralism has changed dramatically in the valley. In the past, for instance, herding was a highly prestigious occupation to them. Now, it is less preferable. This was reflected in Nandakashi's (65 years old woman) statements:

In the past, both owner and herdsmen (hired) used to manage herds in pasturelands. Today, the owner hardly stayed with the herds. All the responsibility is left to hired herdsmen. They do not devote themselves to herds as they did in the past. They do not care about herds. They leave the herds in pasturelands and stay at home in the village for a long time without doing any supervision to them. Owners also do not pay attention to the management and supervision of herds. Today, they are done by the bigreka-manchhe (less capable person) whereas a ramro manchhe (capable person) work in a development program, do business and work in offices or schools or go to foreign countries for labor work.

Nandakashi's remark spells out that the peoples' perceptions about work have undergone a lot of changes in the valley. The old generation wants that their children take responsibility to keep herding alive, but the younger generation of herding families are less interested to take up herding and prefer to do other works that offer better amenities which is also common in the other parts of the

12. The 2011 census reported that about $69.27 \%$ of populations have attended formal education in the Nhāson Valley \{Central Bureau of Statistics (CBS), 2014\}.
Himalaya (Bishop, 1998; Dorji et al., 2020) as well as Alps (Jurt et al., 2015). In my visits in 2012 and 2018, I did not find a person, who completed school level education, totally engaged in herding in the valley. Most of them were found to engage in government and non-government jobs and hotel-business at the trekking route. Some were involved in seasonal work created by infrastructure development programs like road, drinking water supply, and building constructions. During the Himalayan herbs season, they collected herbs from high altitude regions and sold them to local traders. Some educated young males had gone to foreign counties like East Asia, South Korea, Japan, Europe, and America for searching better livelihood ${ }^{13}$.

\section{Tourism and Decline of Cho Herding}

Manang remained as an isolated valley but not closed for foreigners until the late 1950s (van Spengen, 1999; Subedi \& Chapagain, 2011). From the early 1960s to the late 1970s, Manang, including the Nhāson Valley, was closed for tourists, particularly foreigners due to khampa ${ }^{14}$. It was re-opened for foreigners in 1977. Thereafter, the Annapurna round circuit of Manang became a popular destination for tourists. At that time, tourism was a very new phenomenon in the valley. Villagers saw risk in the occupation to sustain their livelihood by engaging in it. By the mid-1990s, only a few households were involved in hotel-business and agro-pastoralism simultaneously. On April 12, 1996, the government declared the year 1998 as 'Visit Nepal 98' to further enhance the image of Nepal as a special destination for visitors. The declaration supported enhancing the flow of tourists in Nepal including the valley. Some households saw their future in tourism-based business and started to construct new hotels and lodges for tourists on the trails of trekking route of the Annapurna round circuit such as Tal, Khotro, Dharapani, Bagarchhap, Danakyu, Timang, and Koto. In 1991, the Manasulu round, from Aarughat of Gorkha district and Dharapani of the Nhason Valley, was declared as a new trekking circuit by the government. However, the flow of tourists could not see in the early years. It was only increased in the late 2000s. Thereafter, Tilche villagers opened new hotels and tea shops in the trail of Manasulu round circuit like Ghya, Surki, Karte, Yak Kharka, and Bimthang.

Despite the closed of salt-grain trade in the valley, a few households were still keeping cho herds for the transportation of goods. I have already mentioned that cho herd was completely displaced from the valley in 1981 . Tourism was one reason that demanded new products like soaps, noodles, biscuits, beer, canned juice, gas cylinder. The valley relied on Beshisahar, the nearest market, for those items. However, there was no motorable road for transportation. The options for the transportation of goods

13. Manarasi Gurung was the last shepherd of Nache. He sold his sheep flock when his son applied for a job in South Korea under the Employment Permit System (EPS) in 2012. 14. Khampa is the 'name' of a group of people who come from Kham region in Tibet. They were followers of Dalai Lama who flew away after controlled over Tibet by China. They established camps in Mustang and Manang. The government of Nepal had the policy to keep them out from the contact of foreigners, especially the USA. 
from Beshisahar to the valley were carrying on either human's back or animals' back. Due to the hot climate, yak and cho were not suitable for the new transportation route. They were looking for new livestock that could be climatically suitable as a packed animal to carry goods from lower altitude to higher altitude. They saw such physiological character in mules. Thereafter, a cho herder invested in mules by selling their cho herd, and later other villagers also invested in mules. In 2012, Manang was connected with Beshisahar through a motorable road which displaced a large number of mule herds from the valley ${ }^{15}$. Mule herders invested the money that came from selling mules in public transportation. In 2018, 10 out of 16 villages were connected through motorable road. Out of six, two villages (Nache and Gherang) were less than onehour walking distance from the motorable road and four villages, namely, Ghya, Surki, Karte, and Bimthang were quite far from the motorable road. The expansion of road is gradually displacing traditional means of transportation which is not new phenomena in Nepal (Blaikie et al, 1980).

Tourism have brought both opportunities (like diversification of livelihood, mew market for agro-livestock products and job) and challenges in agro-pastoralism. Some households have run both hotel business and agropastoralism together whereas some households have left it after involving in business who could not see more economic benefit. It led to the crisis of agro-pastoralism in the valley.

\section{Rebirth of Yak Herding}

In the valley, yak herding again revived in 2003. In my discussion with herders and villagers, I found that three socio-political events seem responsible for the revival of yak herding in the valley. They were - The 1990 Political Change, the Janajati/Adivasi (indigenous nationalists) Movement of 1991, and the Maoist Movement (19962006). The 1990 Political Changes provided more religious and cultural freedom to ethnic groups (Guneratne, 2002). The Janajati/Adivasi Movement promoted strengthening ethnic groups' own culture and to rectify the discrimination suffered by them in all spheres of social life (Toffin, 2009). He further said that the Maoist Movement also hijacked the Adivasi movement agenda to fulfill their political aim. These events produced new kinds of discourses and consciousness to revive lost culture among ethnic groups of Nepal including Gurungs of the Nhāson Valley (Poudel, 2016). The change and movements uprooted some of the existing Hindu values and beliefs, i.e., yak as the same species of a cow that imposed by the former state mechanism. In the Rana period, for example, the state defined yak as the same genesis as a cow which was continued until the overthrown of the active monarchy system in 1990 . By the end of the $20^{\text {th }}$ century, the Gurungs of Nhāson reinterpreted yak and cow as different genesis. They have considered yak as a Tibetan cattle species, rather than a Hindu's cow. Then, they have restarted to eat yak-meat. The redefinition of yak ultimately led to higher

15. By 2010, there was at least one mule herd in each village except Tache and Thanchok. Besides two herds, others were sold before the valley was connected with the motorable road in September 2012. demand for yak's meat among the people of Nhāson. In the valley, I found that yak has a higher economic value and a more and quick return than other cattle and livestock ${ }^{16}$ which motivated them to invest in yak herding. At Nache village, it was started in 2008. At that time, there were only 20 heads of yak (including male, female, and kids) with one herd. Shortly, the number of yak herds and heads were increased dramatically. In 2012 there were 5 herds with 88 heads of yak and increased by 2.57 times and reached 227 heads with 13 herds in 2018. The rapidly increasing number of yak and its herds seem that yak herding is appearing as a lucrative livelihood option in the village.

Besides, economic and climatological reasons, cultural beliefs and values are also responsible for the revival of the yak herding in the valley. There is a cultural taboo on meat. The Gurungs in the valley are highly influenced by Hindu ideology. As a result, they do not eat cow-meat. Sapri Ghale, a sub-clan of Charthare Gurungs, does not eat mutton culturally ${ }^{17}$. Charthare (four-clans) Gurungs do not eat buffalo-meat for social reasons. By avoiding it, the Charthare Gurungs could able to separate themselves and stay superior to Sohrathare (sixteen-clans) and establish a good relationship with the ruling classes. They could not uplift their status without dropping those habits which inevitably ranked them at a lower status in society (Poudel, 2016). In the diverse worldviews on meat among Gurungs, yak-meat is culturally acceptable to all clans of Gurungs in the valley that has also supported to promote of yak herds. In 2018, I did not see the market for yak meat outside the valley. The only consumers were the local people. The lack of a market for yak meat outside the valley will raise the question of the sustainability of yak herding in the valley.

\section{Climate Change and Herding}

Climate change is posing challenges in herding in the Nhāson Valley (Poudel, 2020b). An annual increased rate of maximum temperature is $0.0334^{\circ} \mathrm{C}$ (Poudel, 2020a). Similarly, precipitation patterns, particularly snowfalls, is being erratic and less intensive and shifting beyond ideal time (Poudel, 2018) ${ }^{18}$. Consequently, the ideal landscape of vegetation and animals, including the landscape of domestic plants like fruits, vegetables, and cereal crops and their productivity and animals, particularly yak is being shifted toward higher altitudes.

The herders felt three major challenges, the scarcity of grasses, dried up of water, and loss of the traditional habitat of yak due to global warming (Poudel, 2020b). Herders experienced that the thorny and shrub flora of the lower elevations is slowly making incursions into grazing lands, and few species historically known as quality grasses to their livestock from these habitats could no longer be located. It is predicted that about 16 and 18

16. In 2012, the local market price of a four years old yak was 50,000 to 65,000 which is 4 to 5 times higher than goat/sheep and ox; 10 to 15 times higher than a cow; 3 to 4 times higher than cho.

17. According to Sapri Ghale myth, their ancestor was survived by shucking goats' milk when her mother was died after giving his birth. Today, they relate goats as their brother.

18. Villagers informed me that the 2018 winter was the year without snow at the village which would not be in the past. 
percent of endemic angiosperm species would be likely to lose their habitat by 2050 and 2070 respectively (Manish et al., 2016). Similarly, they also felt the scarcity of water on meadows. They have been noticing the dried up of springs and rivulets. However, they described the changes in the water resources in pasturelands by linking with the movement of herds rather than the amount or quantity of water flow in springs or rivulets as natural sciences do.

In the past, water would not be a scarcity in our grazing lands. Springs would start to sprout March/April along with melting snowfall and it would remain intact until mid-November. Thus, we had to neither wait more days to move our livestock up in grazing lands nor hurry to move down the herds earlier. Nowadays there is no water for our livestock. It only begins to regenerate after the onset of rains in mid-June and almost dries up by the end of September and early October. We have to wait more days to move livestock up in pasturelands and hurry down. (K. Gurung, 46 years old of Unash)

Herders' experiences told that the impact of the scarcity of water in meadows was not the same. It varies from livestock to livestock. About it, a 46 years old herder remarked, "Today, we are in a dilemma. Yak will die with low altitude sickness if they keep at lower altitude pasturelands in the spring, and they will die with dehydration if they move up in higher pasturelands." The embedded experience of the herder tells us that yak herding is at higher risk in the mountain regions due to increased temperature.

Loss of yak in the Himalayan region is not only a threat to livelihood. The lives of human communities around this region are so intertwined with yak that these groups name their clans, areas, mountains, rivers after yak (Keliang \& Changxin, 2004; Pandit, 2017), yak for legend and song (Hellman, 2019). Except for place name after yak, I did not find any names of clans, rivers and mountain, and legend associated with yak. They also did not make woolen blankets from yak's wool. However, indigenous knowledge of the local ecosystem and life-narratives were associated with yak and yak herding (Poudel, 2020b). I also found the name of the business house after yak. Thus, yak is more than Himalayan biological species; it is the economy, culture, identity as well sense of place of the Himalayan people that they lost with the displacement of the yak herd nearly seven decades ago.

Ongoing climate change uprooted the traditional habitat of yak in the valley. For instance, Nache herders kept their yak at Nache village and its surrounding $(2,400$ masl $)$ in the winter until the late $1970 \mathrm{~s}$. Since then, they could not move their yak down from Kromche (3,100-3,200 masl) due to increased temperature, so they opted to keep their yak at Kromche. The increased temperature again challenged to keep yak at Kromche. To cope with the challenge of increased temperature, they have again begun to keep yak herds at Wabu and Wagreche grazing lands (about 3,600 to 3,700 masl) in winter. This shows that Nache herders have been shifting the habitat of yak in higher altitudes to cope with the risk created by climate change. In other words, the herders are not passive in coping with risks, in particular habitat risk, imposed by anthropogenic climate change. However, questions definitely arose. Is shifting the habitat with every increased temperature always possible? Or can shifting the location to a higher altitude be sustainable for herding? In the trans-Himalayan region, the shifting of the location of yak to a higher altitude cannot be a long term adaptive strategy for them. It has a limitation. Once the day would come; there would be no higher pastures to shift their yak in the mountain region. If that happens, there would be no more yak culture embedded with the mountain region (Poudel, 2018).

\section{Community Forest and Plantation of Cash Crops in Barren Land}

As the rhythms, seasons, and social life in the Himalayan are closely interlinked to each other (Poudel, 2020c). Except for yak, cho/cho-aama, and horse, herders used to move their zebu cattle, sheep, and goat herds to Lamjung, a winter pasture, both to protect them from cold and feed grasses. In Lamjung, they used to graze their livestock inside community forests and private fallow lands. It was traditional practices. Since 2016, some community forest user groups have planted cardamom insider community forests as an income-generating activity in their initiative. Similarly, private landowners have also planted cardamom in their lands where they used to plant maize and paddy. Such activities have restricted the herders to graze the herds both in community forests and private lands. An informant said,

In the past, the lowland dwellers used to welcome to our herds to graze in their barren lands to increase the productivity. Nowadays, we paid the penalty for grazing livestock. For instance, a herder of my village paid fifteen thousand Nepali currency to a landowner for destroying a few plants of cardamom planted in private land last winter (2017). The next summer (2018) he sold his herd. (D. S. Gurung, 54 years old man, Unash)

The herders have felt obstacles to graze their livestock in lower altitudes along with the intervention of highvalue crops - cardamom in community and private lands. Regards to it M. B. Gurung (73 years old herder) said,

In the past, they (the farmers of Lamjung) used to invite us with great respect to grazing our sheep/goat herds in their farmlands for manure. They would provide food for us. The situation was not like the past. It has changed. They do not pay attention to us. They see us as crop-destroyers rather than manure-providers.

These are the representative cases of how the market economy and concept of community forest (plantation of the high-value crop for individual profit) appears as an obstacle for the continuity of traditional cattle and sheep/ goat herding for the Nhason dwellers which was also reported from other parts of the mountain region (Bhusal et al., 2018).

\section{Conclusion}

The data presented in the text reveal that herding, one of the traditional ways of living, has been transformed, and is still being transformed in the Himalayan region of Nepal due to encounters with the wider politicaleconomic process. If we ignore political and economic 
processes, we cannot get a holistic picture of the herding and its transformation. For instance, border seal between China and Nepal in 1957 and incursion of cheap Indian salt played an important role for declining of yak and cho herding. Similarly, the privilege to free trade to neighbor communities, expansion of modern education, tourism, open of labor market in the Middle East, South Korea, Japan for youth and plantation of the high-value cash crop in grazing lands by neighboring communities contributed for declining of cattle and sheep/goat herding. On the contrary, The Political Change of 1990, The Ethnic Movement of 1991, and The Maoist Movement from 1996 to 2006 supported the revival of yak herding that was lost in 1957. This indicate of the fact that herding is not purely a local and isolated phenomenon; it is a product of a wider political-economic process. The nexus between local and global is, therefore, important and essential to understanding the underlying complexity of human-nature as Biersack, (2006) stated.

This ethnographic study reflects that there are huge challenges in the sustainability of transhumance herding in the Himalaya, although market economy and state intervention programs and policy have brought new options for livelihood opportunities to the Himalayan dwellers. Only a handful of people could able to grasp the opportunities but poor and marginalized groups are still behind. Moreover, the disturbance in the ecological system by global warming and the concept of the plantation of high-value crops in community forests and private lands also possesses great challenges in herding for the high mountain dwellers. Recently, yak herding has revived but its sustainability always questions due to the limited market for yak meat ${ }^{19}$, rapidly increasing global temperature and lack of policy to keep the young generation in the village as a successor to take up herding. All these factors reflect of the fact that herding in the Himalaya, in which the livelihood and culture of human communities around this region are so intertwined, is at high risk and it demands an alternative set of strategies for a policy framework for intervention.

\section{Acknowledge:}

I am grateful to the people of Nhāson for sharing their experiences. I also acknowledge the University Grant Commission, Nepal for funding this work. I am also grateful to anonymous reviewers for their healthy comments and suggestion. I also thank the editorial team of Dhaulagiri Journal of Sociology and Anthropology for accepting my manuscript.

\section{Funding:}

This research was funded by the University Grant Commission (UGC), Nepal.

\section{Conflict of Interest:}

Researcher does not have any conflict of interest.

19. The lowland dwellers do not eat yak meat because of their worldview to see yak and the highland dwellers do not prefer to buy it due to more expensive than cattle.
Ethical Conduct of Research:

I declare that the research was conducted ethically.

\section{References}

Aryal, A., Brunton, D., Pandit, R., Rai, R. K., Shrestha, U. B., Lama, N., \& Raubenheimer, D. (2013). Rangelands, conflicts, and society in the Upper Mustang region, Nepal. Mountain Research and Development, 33(1), 11-18. https://doi.org/10.1659/ MRD-JOURNAL-D-12-00055.1

Banjade, M., \& Paudel, N. (2008). Mobile pastoralism in crisis: Challenges, conflicts and status of pasture tenure in Nepal mountains. Journal of Forest and Livelihood, 7(1), 49-57.

Basnet G. and Chaudhary, R. P. (2017). Indigenous system of pastureland management: A case of Limi in the Kailash sacred landscape, Nepal. In M. Karki, R. Hill, D. Xue, W. Alangui, K. Ichikawa and P. Bridgewater (eds). Knowing our lands and resources: Indigenous and local knowledge and practices related to biodiversity and ecosystem services in Asia. Pp. 8592. UNESCO

Bauer, K. M. (2004). High frontiers: Dolpo and the changing world of Himalayan pastoralists. Columbia University Press.

Bhusal, P., Banjade, M. R., \& Paudel, N. S. (2018). Pastoralism in crisis: Mounting challenges in herding system in high altitude region of Nepal. Journal of Forest and Livelihood, 16(1), 56-70. https://doi. org/10.3126/jfl.v16i1.22882

Biersack, A. (2006). Introduction. In A. Biersack and J. B. Greenberg (eds.) Reimagining political ecology (pp. 3-40). Duke University Press.

Bishop, N. H. (1998). Himalayan herders. Harcourt Brace College Publishers.

Blaikie P., Cameron J., \& Seddon D. (1980). Nepal in crisis: Growth and stagnation at the periphery. Oxford University Press.

Brower, B. (1993). Sherpa of Khumbu: People, livestock, and landscape. Oxford University Press.

CBS 2014. National Population and Housing Census 2011 (Village Development Committee/Municipality) Manang. Government of Nepal

Chhetri, P. (2014). Livelihood strategies of people in the Himalayan region of Nepal: A study in the villages of eastern Manang. Independent Study Project (ISP) Collection. https://digitalcollections.sit.edu/isp_ collection/1831

Dorji, N., Derks, M., Groot Koerkamp, P. W. G., \& Bokkers, E. A. M. (2020). The future of yak farming from the perspective of yak herders and livestock professionals. Sustainability, 12(10), 4217. https://doi. org/10.3390/su12104217

Fisher, J. F. (1987). Trans-Himalayan traders: Economy, society \& culture in northwest Nepal. Motilal Banarsidass.

Goldman, M. J., \& Turner, M. D. (2011). Introduction. In M. J. Goldman, P. Nadasdy and M.D. Turner (eds.) Knowing Nature: Conversations at the Intersection of Political Ecology and Science Studies (Pp. 1-23). University of Chicago Press. 
Government of Nepal, (2016a). Nepal trade integration strategy: Executive summary and action matrix. Ministry of Commerce

Government of Nepal, (2016b). Agriculture development strategy (ADS) 2015 to 2035. Ministry of Agricultural Development

Guneratne, A. (2002). Many tongues, one people: The making of Tharu identity in Nepal Cornell University Press.

Gurung, H. (1980). Vignettes of Nepal. Sajah Prakashan/ Sahayogi Press.

Gurung, N. J. (1976). An Introduction to the Socioeconomic Structure of the Manang District. Kailash IV(3), 295-310. https://doi.org/10/227238

Hellman, R. (2019). The last yak song: A recount of the decline of pastoral herding in lower Mustang. Independent Study Project (ISP) Collection. https:// digitalcollections.sit.edu/isp_collection/3185

HMG/N. (2000). Topo-maps of Nepal: sheet no. 2884-06 \& 2884-10. Survey Department

HMG/N. $\{2057 / 58$ BE (2000-2002)\}. Annual booklet on livestock management (in Nepali). Ministry of Agriculture and Livestock.

Jurt, C., Häberli, I., \& Rossier, R. (2015). Transhumance Farming in Swiss Mountains: Adaptation to a Changing Environment. Mountain Research and Development, 35, 57-65. https://doi.org/10.1659/ MRD-JOURNAL-D-14-00022.1

Ke-liang, W., \& Chang-xin, W. (2004). Documentation and mining of yak culture to promote a sustainable yak husbandry. Undefined. /paper/Documentation-andmining-of-yak-culture-to-promote-Ke-liang-Changxin/f0eb5a92ff76dfb73e4aac0128e3246124443a1a

Levine, N. E. (1989). The dynamics of polyandry: Kinship, domesticity, and population on the Tibetan border. University of Chicago Press.

Manish, K. Telwala1, Y., Nautiyal, D. C. \& Pandit, M. K. (2016). Modelling the impacts of future climate change on plant communities in the Himalaya: A case study from Eastern Himalaya, India. Model Earth System Environmen 2:92. doi 10.1007/s40808-016-0163-1

Messerschmidt, D. A. (1974). Gurung shepherds of the Lamjung Himalaya. In Objets et Mondes, numéro consacré aux "Hommes et Milieux Himalayens" XIV,4, 307-316

Messerschmidt, D. A. (1976). Ecological change and adaptation among the Gurungs of the Nepal Himalaya. Human Ecology, 4(2), 167-185.

Miller, D. J. (1995). Herds on the move: Winds of change among pastoralists in the Himalayas and on the Tibetan plateau. ICIMOD.

Miller, D. J. (1998). Fields of grass: Portraits of the pastoral landscape and nomads of the Tibetan Plateau and Himalayas. ICIMOD.

Pandey, M. R., \& Chetri, M. (2005). Nomads and pastoralism: Linkage with biodiversity conservation in upper Mustang, Nepal. Our Nature, 3(1), 42-49. https://doi.org/10.3126/on.v3i1.333

Pandit, M. K. (2017). Life in the Himalaya: An ecosystem at risk. Harvard University Press.

Poudel, J. M. (2016). Climate change, farming, and livestock: A study of local knowledge, perception and responses among the people of Nhāson, Manang. Tribhuvan University.

Poudel, J. M. (2018). Pond becomes a lake: Challenges posed by climate change in the trans-Himalayan regions of Nepal. Journal of Forest and Livelihood, 16(1), 87-102. https://doi.org/10.3126/jfl.v16i1.22884

Poudel, J. M. (2020a). Human dimensions to climate change: Insights from case study in the Nhāson Valley of Nepal Himalaya. Journal of Tourism and Himalayan Adventures, 2, 42-56.

Poudel, J. M. (2020b). Pond becomes a lake: Challenges for herders in the Himalayas. Practicing Anthropology, 42(2), 30-35. https://doi.org/10.17730/08884552.42.2.30

Poudel, J. M. (2020c). The rhythms of life in the Himalaya: Seasonality and sociality among the Gurung people of the Nhāson Valley. International Journal of Anthropology and Ethnology, 4(1), 10. https://doi. org/10.1186/s41257-020-00036-z

Schrader, H. (1987). Trading patterns in the Nepal Himalayas. Internationales Asienforum, 18, 253-278.

Spoon, J. (2013). From yaks to tourists: Sherpa livelihood adaptations in Sagarmatha (Mount Everest) national park and buffer zone, Nepal. In Lozny, L. R. (Ed.) Continuity and change in cultural adaptation to mountain environments: From prehistory to contemporary threats (pp. 319-340). Springer Science \& Business Media.

Stevens, S. F. (1993). Claiming the high ground: Sherpas, subsistence, and environmental change in the highest Himalaya. University of California Press.

Subedi, B. P., \& Chapagain, P. S. (2011). Tourism development in upper Manang valley of Annapurna region. Nepal Tourism and Development Review, 1(1), 56-68. https://doi.org/10.3126/ntdr.v1i1.7370

Toffin, G. (2009). The janajati/adivasi movement in Nepal: Myths and realities of indigeneity. Sociological Bulletin, 58(1), 25-42. https://doi. org/10.1177\%2F0038022920090103

van Spengen, W. (1987). The Nyishangba of Manang: Geographical perspectives on the rise of a Nepalese trading community. Kailash, XIII(3-4), 134-282. https://doi.org/10/227353

van Spengen, W. (1999). Tibetan border worlds: A geohistorical analysis of trade and traders. John Wiley \& Sons.

von Fürer-Haimendroef, C. (1978). Trans-Himalayan traders in transition. In J. F. Fisher (eds.) Himalayan anthropology: The Indo-Tibetan interface, (pp. 339357); Mouton Press.

Jiban Mani Poudel https://orcid.org/0000-0001-63834983 holds Ph.D. from Tribhuvan University (TU), Nepal in 2016. He is a lecturer at the Central Department of Anthropology, Tribhuvan University of Nepal. His works focus on the human-environment relationship, livelihood, and kinship studies. Currently, his area of interest is on human dimensions on climate change in the Himalayan region, especially focusing on documentation on local knowledge, perception and adaptation, language, and climate change.

Email: jiban.poudel@cda.tu.edu.np 